\title{
Low temperature preparation of nanocrystalline solid solution of strontium barium niobate by chemical process
}

\author{
ASIT B PANDA, AMITA PATHAK and PANCHANAN PRAMANIK* \\ Department of Chemistry, Indian Institute of Technology, Kharagpur 721 302, India
}

\begin{abstract}
Sr}_{x} \mathrm{Ba}_{1-x} \mathrm{Nb}_{2} \mathrm{O}_{6}$ (with $x=0.4,0.5$ and 0.6 ) powders have been prepared by thermolysis of aqueous precursor solutions consisting of triethanolamine (TEA), niobium tartarate and, EDTA complexes of strontium and barium ions. Complete evaporation of the precursor solution by heating at $\sim 200^{\circ} \mathrm{C}$, yields in a fluffy, mesoporous carbon rich precursor material, which on calcination at $750^{\circ} \mathrm{C} / 2 \mathrm{~h}$ has resulted in the pure $\mathrm{SBN}$ powders. The crystallite and average particle sizes are found to be around $15 \mathrm{~nm}$ and $20 \mathrm{~nm}$, respectively.
\end{abstract}

Keywords. Low temperature preparation; nanocrystalline solid solution; $\mathrm{Sr}_{x} \mathrm{Ba}_{1-x} \mathrm{Nb}_{2} \mathrm{O}_{6}$.

\section{Introduction}

Since 1980, strontium-barium-niobate $\left(\mathrm{Sr}_{x} \mathrm{Ba}_{1-x} \mathrm{Nb}_{2} \mathrm{O}_{6}\right.$, with $0.25 \leq x \leq 0.75$ ) ceramics solid solutions (Nagata et al 1981; VanDamme et al 1991) have gained immense attention as possible substitutes for their single crystals in many technological applications because of their low cost, and easy fabrication into larger sizes and more complex shapes. Their potential applications, in both electrical and optical fields, generally demand of a uniform, fine-grained microstructure with nearly theoretical density in the material. This however, is difficult to achieve with the help of simple pressureless sintering because of abnormal grain growth (Fang and Wu 1995; Lee and Fang 1998) arising from high calcination temperatures $\left(\leq 1150^{\circ} \mathrm{C}\right)$ that are requisites for preparations through conventional solid-state reaction of the reactants. The use of solution based chemical synthesis methods ensures atomic level mixing of the reactants and hence can circumvent the high calcination temperature requirements associated with the conventional solid-state methods. Unfortunately, the preparation of dense SBN ceramics through chemical synthesis methods gets complicated (Das and Pramanik 2000) by the moisture sensitivity and easy hydrolysis of the niobium sources (Choi et al 1990; Narender and Messing 1997; Sekar and Halliyal 1998) (such as niobium pentachloride and niobium ethoxide etc). In this paper we report a novel chemical route for the preparation of single-phase, nanocrystalline $\mathrm{Sr}_{x} \mathrm{Ba}_{1-x} \mathrm{Nb}_{2} \mathrm{O}_{6}(x=0 \cdot 4,0.5$ and $0 \cdot 6)$ powders using an aqueous solution of niobium-tartarate complex as the source of niobium, which overcomes the problems associated with the reported sources of niobium. The route involved the complete evaporation of the aqueous precursor

\footnotetext{
*Author for correspondence
}

solution of the respective metal-complexes and triethanolamine (TEA) to obtain a carbonaceous precursor mass, which was dried, ground to powders and then calcined to obtain the desired SBN powders.

\section{Experimental}

The raw materials that were used for the preparation of the ceramic SBNs were $\mathrm{Sr}\left(\mathrm{NO}_{3}\right)_{2}, \mathrm{Ba}\left(\mathrm{NO}_{3}\right)_{2}$, EDTA, TEA, and niobium tartarate. The solution of the niobiumtartarate complex was prepared in the laboratory from its hydrated oxide $\left(\mathrm{Nb}_{2} \mathrm{O}_{5} \cdot n \mathrm{H}_{2} \mathrm{O}\right)$ and the detail of the preparation process is discussed elsewhere (Das and Pramanik 2000; Panda et al 2002). Stoichiometric amounts of aqueous solutions of $\mathrm{Sr}\left(\mathrm{NO}_{3}\right)_{2}, \mathrm{Ba}\left(\mathrm{NO}_{3}\right)_{2}$, and ammonium EDTA were taken and mixed together to obtain a clear solution of the barium- and strontium-EDTA complexes, where the overall EDTA to metal ion mole ratio in the solution was maintained at unity. Stoichiometric amount of the prepared niobium-tartarate complex solution was then introduced into the solution mixture that was followed by the addition of optimum amounts of TEA solution $(\sim 8-10$ moles, with respect to the total moles of the metal ions). The resulting red coloured, homogeneous solution was set to evaporate (at $\sim 200^{\circ} \mathrm{C}$ ) with constant stirring. The complete dehydration of the solution was accompanied by decomposition of the metalcomplexes and TEA with simultaneous evolution of dense fumes and resulted in a voluminous, fluffy, black organic-based mass. The fluffy carbonaceous precursor material was ground to powders and then calcined at $750^{\circ} \mathrm{C}$ for $2 \mathrm{~h}$ to produce the desired single phase of SBN powders.

\section{Results and discussion}

The DTA of the precursor powders (figure 1) revealed an exothermic thermal effect accompanied by a single step 
weight loss in the TG curve. The exotherm could be assigned to the oxidation of carbonaceous remains of the decomposed metal-complexes and TEA, which was associated with the evolution of various gases, such as $\mathrm{CO}$,

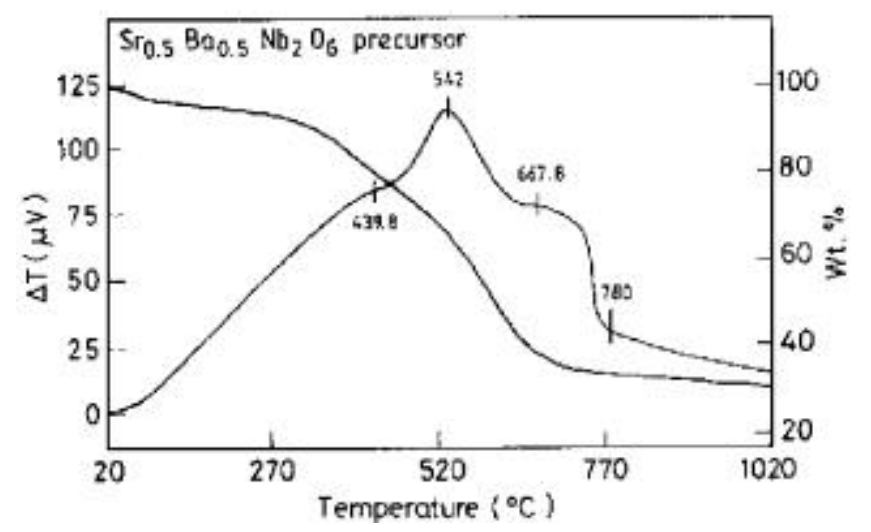

Figure 1. DTA and TG curves of SBN-5 precursors.

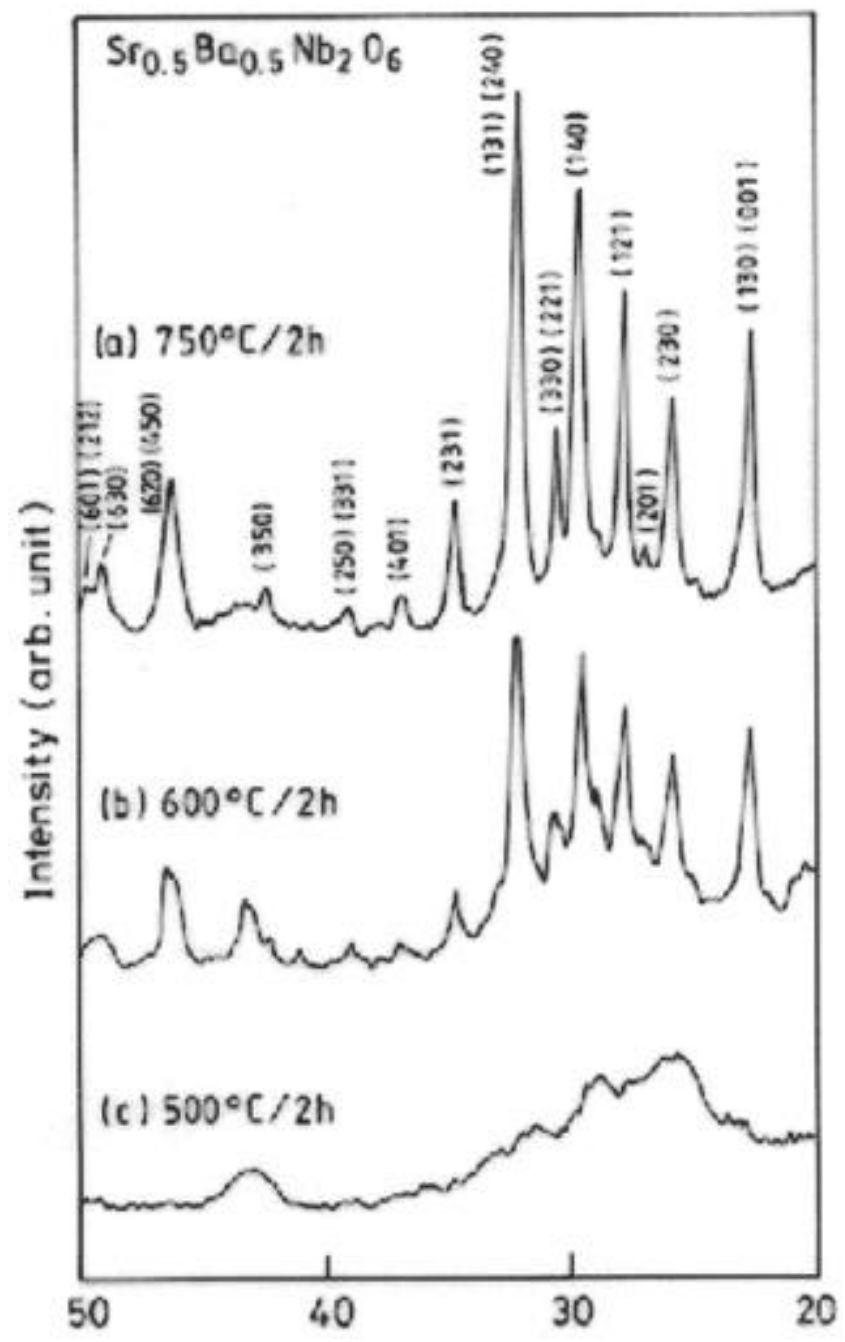

Figure 2. X-ray diffractograms (using $\mathrm{CuK}_{\alpha}$ radiation) of SBN-5 precursors calcined at various temperatures.
$\mathrm{CO}_{2}, \mathrm{NH}_{3}$, water vapour etc, as was reflected from the corresponding TG curve. There was however, no significant thermal effect above $700^{\circ} \mathrm{C}$ and the corresponding TG curves showed no weight loss, implying the formation of the oxides phase at this temperature. X-ray diffractograms (figure 2) of the virgin SBN precursors were observed to be X-ray amorphous and their calcination at $600^{\circ} \mathrm{C}$ and $750^{\circ} \mathrm{C}$ revealed the onset and then their eventual crystallization into the pure SBN phase at the two respective temperatures, without passing through any intermediate (Fang et al 1994) metal-oxide phases/prephase compounds. The crystallite sizes in the calcined powders of varying SBN compositions, were calculated from X-ray line broadening studies using Scherrers' equation (Klug and Alexander 1974). The smallest visible isolated, almost spherical, spots in the bright field transmission electron micrographs (figure 3) were identified as the particle/crystallite agglomerates and their diameters were observed to lie between 15 and $20 \mathrm{~nm}$. The

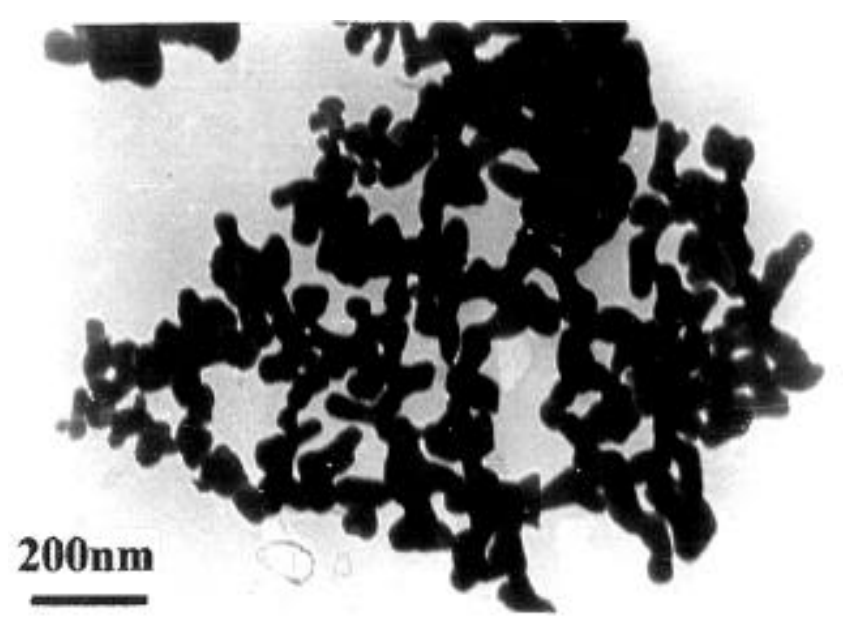

Figure 3. Bright field TEM micrographs of the SBN-5 precursors after calcination at $750^{\circ} \mathrm{C}$ for $2 \mathrm{~h}$.

Table 1. Summary of the powders characteristics of the various SBN compositions.

\begin{tabular}{lcccc}
\hline $\begin{array}{l}\text { SBN } \\
\text { composition }\end{array}$ & $\begin{array}{r}\text { Temp. } \\
\left({ }^{\circ} \mathrm{C}\right)\end{array}$ & $\begin{array}{r}\text { Temp. } \\
\left({ }^{\circ} \mathrm{C}\right)\end{array}$ & $\begin{array}{r}\text { Cryst. size } \\
(\mathrm{nm})\end{array}$ & $\begin{array}{c}\text { Av. particle } \\
\text { size }\end{array}{ }^{\dagger \dagger \dagger}( \pm 5 \mathrm{~nm})$ \\
\hline $\mathrm{Sr}_{0.4} \mathrm{Ba}_{0.6} \mathrm{Nb}_{2} \mathrm{O}_{6}$ & 650 & 725 & $13 \cdot 6$ & 15 \\
$\mathrm{Sr}_{0.5} \mathrm{Ba}_{0.5} \mathrm{Nb}_{2} \mathrm{O}_{6}$ & 600 & 750 & $16 \cdot 2$ & 18 \\
$\mathrm{Sr}_{0.6} \mathrm{Ba}_{0.4} \mathrm{Nb}_{2} \mathrm{O}_{6}$ & 600 & 750 & $16 \cdot 8$ & 20 \\
\hline
\end{tabular}

${ }^{\dagger}$ The minimum calcination temperatures required for obtaining carbon free powders; ${ }^{\dagger}$ minimum calcination temperatures required for the initiation of the respective crystalline phase; ${ }^{\dagger \dagger}$ average crystallite sizes calculated using the Scherrers' formula applied to the various $d_{\mathrm{hkl}}$ lines of the precursor powders that were calcined at their respective crystallization temperatures; diameters of the smallest visible isolated particle/crystallite agglomerate as observed from TEM studies for the precursor powders calcined at their respective crystallization temperatures. 
values of the crystallite size and the average TEM particle size were observed to be the lowest for the $\mathrm{Sr}_{x} \mathrm{Ba}_{1-x} \mathrm{Nb}_{2} \mathrm{O}_{6}$ composition with $x=0.4$ while they were almost same for the compositions with $x=0.5$ and $x=0.6$ (see table 1). The corresponding SAED pattern of the same sample showed distinct rings, characteristic of an assembly of nanocrystallites. The BET surface area of the generated carbon was found to range between 160 and $200 \mathrm{~m}^{2} / \mathrm{g}$. This led us to infer that the precursor material was essentially a matrix of mesoporous carbon.

\section{Conclusions}

Thus, a simple chemical process has been developed for the preparation of nanocrystalline powders of various $\mathrm{Sr}_{x} \mathrm{Ba}_{1-x} \mathrm{Nb}_{2} \mathrm{O}_{6}$ compositions through evaporation of a homogeneous aqueous precursor solution of soluble niobium-tartarate complex, EDTA complexes of $\mathrm{Sr}^{2+}$ and $\mathrm{Ba}^{2+}$ ions, and TEA. The use of soluble niobium-tartarate complex as the niobium source was found to be superior alternative for the preparation of any niobium-based oxides since it can overcome the problems of moisture sensitivity and hydrolysis that are usually associated with the other reported sources of niobium. The calcination of the precursors, that were obtained from the complete dehydration of the precursor solutions, at external temperatures as low as $750^{\circ} \mathrm{C}$ directly resulted in the nanocrystals of the SBN phase without passing through any intermediate phase. The direct crystallization of the SBN phase from the precursor mass can be attributed to the formation of nascent metal-oxides embedded in the highly polar matrix of the generated mesoporous-carbon. And the heat generated due to the combustion of the carbonaceous residues obtained from the decomposition of
TEA and metal-EDTA complexes reduced the external temperatures required for the formation of the SBN phase.

Thus, it can be concluded that the developed single step chemical method is a simple and a minimal thermal budge process that is suitable for the preparation of any niobium-based nanocrystalline, ceramic mixed-oxide powders.

\section{Acknowledgement}

The authors are grateful to the Council of Scientific and Industrial Research, New Delhi, for the financial grant offered in support of this work.

\section{References}

Choi J H, Woo J S, Hong S G and Kim D J 1990 Mater. Res. Bull. 25283

Das R N and Pramanik P 2000 Mater. Lett. 467

Fang T T and Wu N T 1995 J. Mater. Sci. 303376

Fang T T, Wu N T and Shaiau F S 1994 J. Mater. Sci. Lett. 13 1746

Klug P and Alexander L E 1974 in X-ray diffraction procedures for polycrystalline and amorphous materials (New York: Wiley) 2nd edition

Lee W J and Fang T T 1998 J. Am. Ceram. Soc. 811019

Nagata K, Yamamoto Y, Igarashi H and Okazaki K 1981 Ferroelectrics $\mathbf{3 8} 853$

Narender Y and Messing G L 1997 J. Am. Ceram. Soc. 80915

Panda A B, Pathak A and Pramanik P 2002 Mater. Lett. 52180

Sekar M M A and Halliyal A 1998 J. Am. Ceram. Soc. 81380

VanDamme N S, Sutherland A E, Jones L, Bridger K and Winzer S R 1991 J. Am. Ceram. Soc. 741785 